\title{
Effect of nanotechnology in self-etch bonding systems on the shear bond strength of stainless steel orthodontic brackets
}

\author{
Shaza M. Hammad¹, Noha El-Wassefy², Ahmed Maher³, Shafik M. Fawakerji4
}

DOI: http://dx.doi.org/10.1590/2177-6709.22.1.047-056.oar

\begin{abstract}
Objective: To evaluate the effect of silica dioxide $\left(\mathrm{SiO}_{2}\right)$ nanofillers in different bonding systems on shear bond strength $(\mathrm{SBS})$ and mode of failure of orthodontic brackets at two experimental times. Methods: Ninety-six intact premolars were divided into four groups: A) Conventional acid-etch and primer Transbond XT; B) Transbond Plus self-etch primer; and two self-etch bonding systems reinforced with silica dioxide nanofiller at different concentrations: C) Futurabond DC at 1\%; D) Optibond All-in-One at 7\%. Each group was allocated into two subgroups ( $\mathrm{n}=12$ ) according to experimental time (12 and 24 hours). SBS test was performed using a universal testing machine. ARI scores were determined under a stereomicroscope. Scanning electron microscopy (SEM) and transmission electron microscopy (TEM) were used to determine the size and distribution of nanofillers. One-way ANOVA was used to compare SBS followed by the post-hoc Tukey test. The chi-square test was used to evaluate ARI scores. Results: Mean SBS of Futurabond DC and Optibond All-in-One were significantly lower than conventional system, and there were no significant differences between means SBS obtained with all self-etch bonding systems used in the study. Lower ARI scores were found for Futurabond DC and Optibond All-in-One. There was no significant difference of SBS and ARI obtained at either time points for all bonding systems. Relative homogeneous distribution of the fillers was observed with the bonding systems. Conclusion: Two nanofilled systems revealed the lowest bond strengths, but still clinically acceptable and less adhesive was left on enamel. It is advisable not to load the brackets immediately to the maximum.
\end{abstract}

Keywords: Nanotechnology. Self-etch. Shear bond strength. Scanning electron microscopy. Transmission electron microscopy.

Objetivo: avaliar o efeito das nanopartículas de dióxido de silício $\left(\mathrm{SiO}_{2}\right)$, presentes em diferentes sistemas adesivos, na resistência ao cisalhamento da colagem (RAC) e no modo de fratura de braquetes ortodônticos avaliados em dois momentos. Métodos: noventa e seis pré-molares intactos foram divididos em quatro grupos: A) condicionador ácido convencional e primer Transbond XT; B) primer autocondicionador Transbond Plus; e dois sistemas adesivos autocondicionantes reforçados com nanopartículas de dióxido de silício em diferentes concentrações, C) DC Futurabond a 1\%; D) Optibond All-In-One a 7\%. Cada grupo foi dividido em dois subgrupos ( $\mathrm{n}=12)$, de acordo com o tempo para realização do teste (12 e 24 horas). O teste da RAC foi realizado em uma máquina universal de ensaios. Os resultados do índice de adesivo remanescente foram determinados com um estereomicroscópio. Para determinar o tamanho e a distribuição das nanopartículas, utilizou-se microscopia eletrônica de varredura (MEV) e microscopia eletrônica de transmissão (MET). O ANOVA a um critério foi usado para comparar a RAC, seguido pelo teste post-hoc de Tukey. O teste qui-quadrado foi usado para avaliar os índices de adesivo remanescente. Resultados: a RAC média do Futurabond DC e do Optibond All-In-One foi menor do que a do sistema convencional, de forma estatisticamente significativa; e não houve diferença estatisticamente significativa entre os níveis médios de RAC obtidos nos sistemas adesivos autocondicionantes avaliados nesse estudo. Os menores índices de adesivo remanescente foram observados com o Futurabond DC e o Optibond All-In-One. Não houve, entre os sistemas adesivos, diferença significativa na RAC e nos índices de adesivo remanescente obtidos nos dois tempos de aplicação. Foi observada uma distribuição relativamente homogênea das partículas nos sistemas adesivos. Conclusão: os dois sistemas com nanopartículas demonstraram menor RAC, mas ainda aceitável e com o menor índice de adesivo remanescente no esmalte. É, assim, aconselhável não submeter os braquetes à carga máxima logo após a colagem.

Palavras-chave: Nanotecnologia. Autocondicionantes. Resistência ao cisalhamento. Microscopia Eletrônica de Varredura. Microscopia Eletrônica de Transmissão.

${ }^{1}$ Associate Professor of Orthodontics, Mansoura University School of Dentistry, Mansoura, Egypt.

${ }^{2}$ Assistant Professor of Dental Biomaterials, Mansoura University, School of Dentistry, Mansoura, Egypt.

${ }^{3}$ Assistant Professor of Orthodontics, Mansoura University, School of Dentistry, Mansoura, Egypt.

${ }^{4}$ Graduate student in Orthodontics department, Mansoura University, School of Dentistry, Mansoura, Mansoura, Egypt.

Submitted: April 12, 2016 - Revised and accepted: September 12, 2016
How to cite this article: Hammad SM, El-Wassefy N, Maher A, Fawakerji SM. Effect of nanotechnology in self-etch bonding systems on the shear bond strength of stainless steel orthodontic brackets. Dental Press J Orthod. 2017 JanFeb;22(1):47-56. DOI: http://dx.doi.org/10.1590/2177-6709.22.1.047-056.oar

» The authors report no commercial, proprietary or financial interest in the products
or companies described in this article.

Contact address: Shaza M. Hammad, Department of Orthodontics, School of Dentistry, Mansoura University, El Gomhoria Street, Mansoura, Egypt 35516 E-mail: shazamohammad@yahoo.com 


\section{INTRODUCTION}

Bonding to enamel has always been a challenge in dental materials; Buonocore pioneered the use of acidetch technique in $1955^{1}$ and Newman was the first to recommend this technique in orthodontics. ${ }^{2}$ Despite the reliability and acceptability of phosphoric acid-etching technique, it is necessary to decrease the number of eroded enamel rods and reduce the chair time without affecting the bond strength. ${ }^{3}$

Self-etching primer (SEP) combining the acid-etching and primer have been introduced in orthodontics. Beside being a more simple and time-effective technique - by decreasing the bonding steps and dispensing the need for etching and priming - , it also avoids the undesirable effects of acid-etching and prevents salivary contamination bonding failure. ${ }^{4,5}$ However, traditional multi-procedures etch and prime systems have shown higher shear bond strength (SBS). ${ }^{3,6}$

The development of dental material sciences has introduced nanotechnology in bonding systems. ${ }^{7}$ Nanotechnology or molecular nanotechnology is the production of functional structures and materials in the length scale of approximately $0.1-100$ nanometers $\left(1 \mathrm{~nm}=10^{-9} \mathrm{~m}\right)$ by various physical or chemical methods. ${ }^{8}$ Many theoretical predications based on the potential application of nanotechnology in dentistry have been made in the last 20 years, with varying levels of optimism. ${ }^{9}$

Recently, composite resins containing nanofillers were introduced to reduce shrinkage during polymerization. ${ }^{10}$ It was claimed that nanoparticles (NPs) provide more dimensional stability and reduce surface roughness. On the other hand, silica dioxide $\left(\mathrm{SiO}_{2}\right)$ nanoparticles have been introduced in bonding systems with different shapes, sizes and levels. Futurabond DC (Voco, Cuxhaven, Germany) and Optibond All-in-One (Kerr, Orange, CA, USA) are self-etch bonding systems reinforced with different levels (1\% and $7 \%$ respectively) of spherical $\left(\mathrm{SiO}_{2}\right)$ nanoparticles. The manufacturers claimed that such particles enhance the bond strength to dentin and enamel. ${ }^{7}$

In order to make a successful orthodontic treatment, it is important to assure adequate bond strength. Stress created by clinical procedure, normal mastication forces and the microleakage of the adhesive lead often to bond failure next to orthodontic brackets placement. ${ }^{11,12}$ Prior studies reported that in order to resist short- and longterm forces in the oral cavity, materials must be suffi- ciently strong. ${ }^{13-15}$ Other studies highlighted the necessity of early measuring the bond strength many times within 24 hours. ${ }^{16,17}$

There have been not enough studies to explain the influence of nanotechnology in bonding systems on orthodontic procedures. So, the aim of the present study was to highlight the effect of this technology in self-etch adhesives on the shear bond strength and the mode of failure of stainless steel orthodontic brackets, in comparison with other SEP and conventional acid-etch with primer system after two times intervals (12 - 24 hours).

\section{MATERIAL AND METHODS}

The present sample consisted of 96 human premolars that were recently extracted for orthodontic purpose. The inclusion criteria for selection was: Sound (intact) teeth without dental caries, cavities, restoration, hypomineralized lesion, enamel hypoplasia, fracture or cracks. Following extraction, residues on the teeth were removed and washed away, then the teeth were stored in 0.9 percent $\mathrm{NaCl}$ solution at room temperature.

The root of each tooth was completely embedded in acrylic resin up to cementoenamel junction leaving the crown exposed. Each tooth was oriented so that the buccal surface was parallel to the applied force during SBS test. Blocks were randomly divided into four main groups according to the utilized adhesive system $(n=24)$. Each group was then subdivided randomly into equal two subgroups ( $n=12)$, according to the time of test (12 or 24 hours). Acrylic blocks were color-coded to identify each test group.

Buccal surfaces were cleaned using a slurry of nonfluoridated pumice using rubber cup for 10 seconds, followed by rinsing with water spray and drying for 30 seconds. Stainless steel premolar brackets, 0.022-inch slot with mean area of each base $=11.55 \mathrm{~mm}^{2}$ (3M Unitek, California, USA) were bonded as follows.

\section{Bonding procedures}

The bonding systems used in this study are shown in Table 1.

For group A, the enamel surfaces of each tooth was etched with 37\% phosphoric acid for 15 seconds, rinsed with water, air-dried for 10 seconds and conventional primer Transbond XT was applied, then light-cured for 10 seconds. The adhesive resin Transbond XT was applied to the bracket base and the bracket was placed on 


\begin{tabular}{|c|c|c|c|c|}
\hline Group & Bonding System & Manufacturer & Composition & Lot number \\
\hline Group A & $\begin{array}{l}\text { Conventional } \\
\text { Transbond XT }\end{array}$ & $\begin{array}{l}\text { Etchant - Ivoclar Vivadent, } \\
\text { Schaan, Liechtenstein } \\
\text { Primer - 3M Unitek } \\
\text { California, USA }\end{array}$ & $\begin{array}{l}37 \% \text { phosphoric acid as etchant. } \\
\text { Primer: } \\
\text { Silane-treated quartz, bisphenol A, diglycidyl ether, dimethacrylate, } \\
\text { bis(2-hydroxyethyl ether), dichlorodimethyl silane, silica reaction products }\end{array}$ & T30617 \\
\hline Group B & $\begin{array}{l}\text { Self-etching } \\
\text { Transbond Plus } \\
\text { SEP }\end{array}$ & $\begin{array}{l}\text { 3M Unitek } \\
\text { California, USA }\end{array}$ & $\begin{array}{l}\text { Silane-treated quartz, glass reacted with hydrolyzed silane, } \\
\text { polyethylene glycol, dimethacrylate, citric acid, dimethacrylate oligomer, } \\
\text { silane-treated silica and bisphenol A, diglycidyl ether }\end{array}$ & B579201 \\
\hline Group C & Futurabond DC & $\begin{array}{l}\text { Voco } \\
\text { Cuxhaven } \\
\text { Germany }\end{array}$ & $\begin{array}{l}\text { Liquid 1: } \\
\text { Acid-modified methacrylate (methacrylate ester) } \\
\text { HEMA (2-hydroxyethyl methacrylate) } \\
\text { Camphorquinone (photoinitiator) } \\
\text { Liquid 2: } \\
\text { Water } \\
\text { Ethanol } \\
\text { Silica dioxide }\left(\mathrm{SiO}_{2}\right) \text { nanofiiler (1\%) }\end{array}$ & 1505034 \\
\hline Group D & Optibond All-in-One & $\begin{array}{l}\text { Kerr } \\
\text { Orange, CA } \\
\text { USA }\end{array}$ & $\begin{array}{l}\text { Glycerol phosphate dimethacrylate (GPDM), mono- and di-functional } \\
\text { methacrylate, monomers, HEMA, ethanol, acetone and water as solvents, } \\
\text { fluoride-releasing fillers and silica dioxide }\left(\mathrm{SiO}_{2}\right) \text { nanofillers }(7 \%)\end{array}$ & 5535902 \\
\hline
\end{tabular}

the enamel surface of each tooth and pressed. Excess adhesive was removed around the bracket base and the adhesive was light-cured using Elipar S10 LED curing light (3M ESPE, St. Paul, USA) for 40 seconds (10 seconds from each side, i.e. mesial, distal, occlusal and gingival).

For group B, Transbond Plus was used. A thin layer of SEP was rubbed on the enamel for 15 seconds and evaporated with gentle air, then, the bracket was bonded as in group A. For group C, Futurabond DC single dose was used. It is a self-etch bonding system that consists of two liquids. A drop of liquid A and a drop of liquid B were mixed, then the mixture was rubbed on the enamel surface for 20 seconds, air-dried and light-cured for 10 seconds, then the bracket was bonded as previously described.

For group D, Optibond All-in-One adhesive was used, which is an one-step self-etching bonding system. At first, the bottle was shaken, then the liquid was applied and rubbed on the enamel surface of each tooth for 20 seconds (this procedure was repeated twice), dried with gentle air and light-cured for 10 seconds, then the bracket was bonded.

\section{Shear bond strength (SBS) testing}

After bonding, the specimens were immersed in distilled water and stored for 12 or 24 hours at $37^{\circ} \mathrm{C}$. SBS testing was done using an universal testing machine (Instron 3345, England). The chisel edge mounted on the cross-head of the machine contacted between the bracket base and occlusal wings of the bracket as close to the base as possible, at a speed of $1 \mathrm{~mm} / \mathrm{min}$. The bracket debonding force was recorded in Newton and then the bond strength was calculated in megapascal (MPa) considering the surface area of the bracket.

\section{Adhesive remnant index (ARI)}

After debonding, all the specimens were examined under stereomicroscope (SZ-PT, Olympus, Japan) at X10 magnification, in order to assess adhesive remnants on tooth surfaces using the ARI. ${ }^{18}$ The ARI scores were: $0=$ no adhesive left on the tooth; 1 = less than half of the adhesive left on the tooth, 2 = more than half of the adhesive left on the tooth, and $3=$ all the adhesive left on the tooth. 


\section{Scanning electron microscopy (SEM) examination}

After ARI test, one specimen from each subgroup was randomly selected for scanning electron microscopic (SEM) evaluation to assess the distribution of bonding materials on enamel surface. The root and lingual part of the crown was dissected using Isomet low speed (Buehler, Lake Bluff, IL, USA) under abundant irrigation. The specimens were cleaned in distilled water with ultrasonic agitation for 30 minutes and gently air-dried, mounted on aluminum stubs and sputter coated with gold prior to SEM examination (JEOL, JSM-6510LV, Japan) operated at an accelerating voltage of $30 \mathrm{kV}$. The examination of all groups was done at X1000 magnification and at X5000 magnification to determine the distribution of nanofillers more accurately. Representative images of different specimens were digitally captured and are presented in Figures 1 and 2.
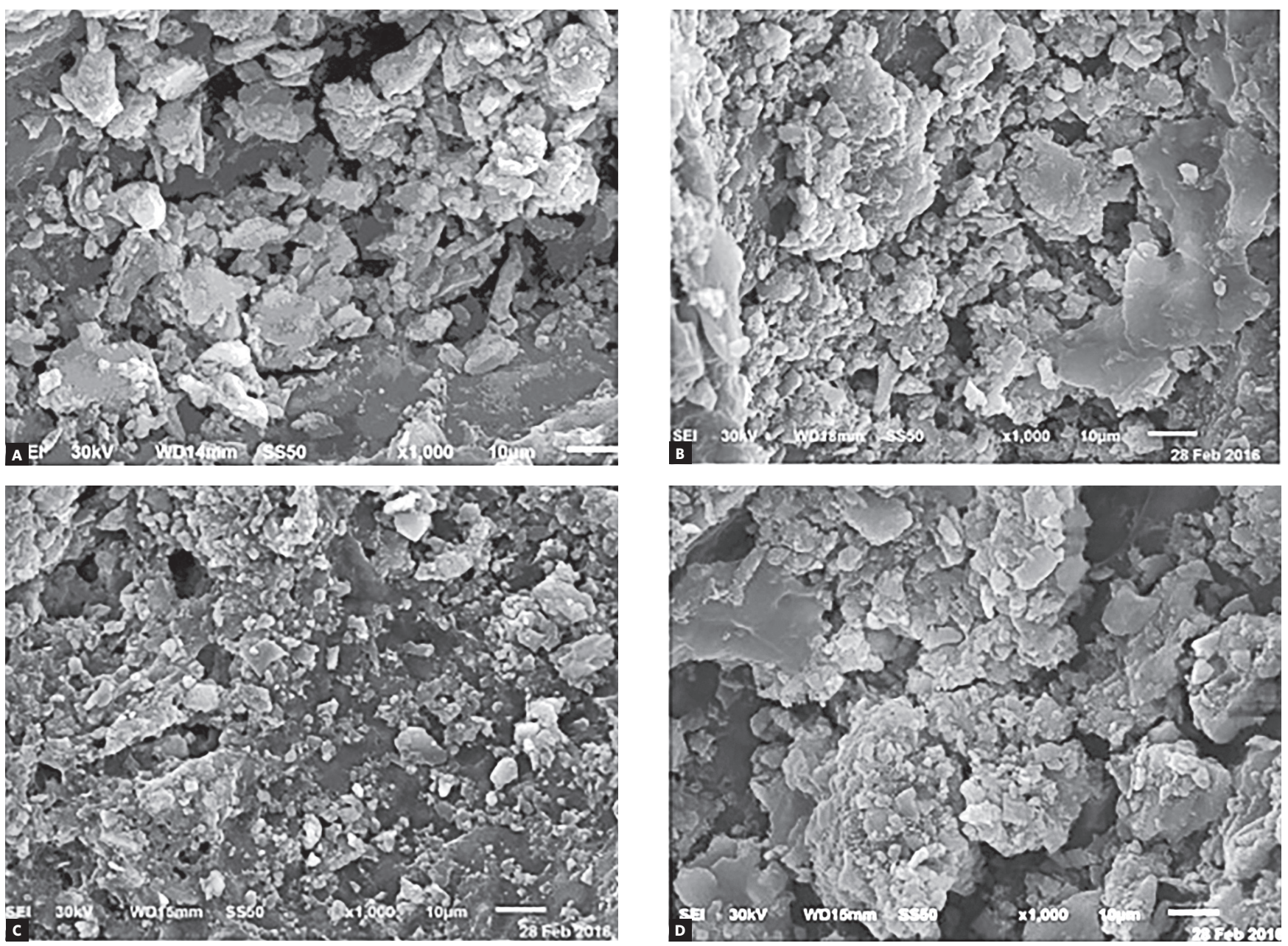

Figure 1 - Representative SEM photomicrographs of: conventional bonding system after 12 hours (A) and 24 hours (B); Transbond Plus system after 12 hours (C) and 24 hours (D) 
Transmission electron microscopy (TEM) examination

A drop from each utilized bonding system was loaded on carbon coated copper grid (200-mesh) and examined by TEM (JOEL, JEM-2100, Japan) to determine the size and distribution of the fillers within each bonding agent (Fig 3).
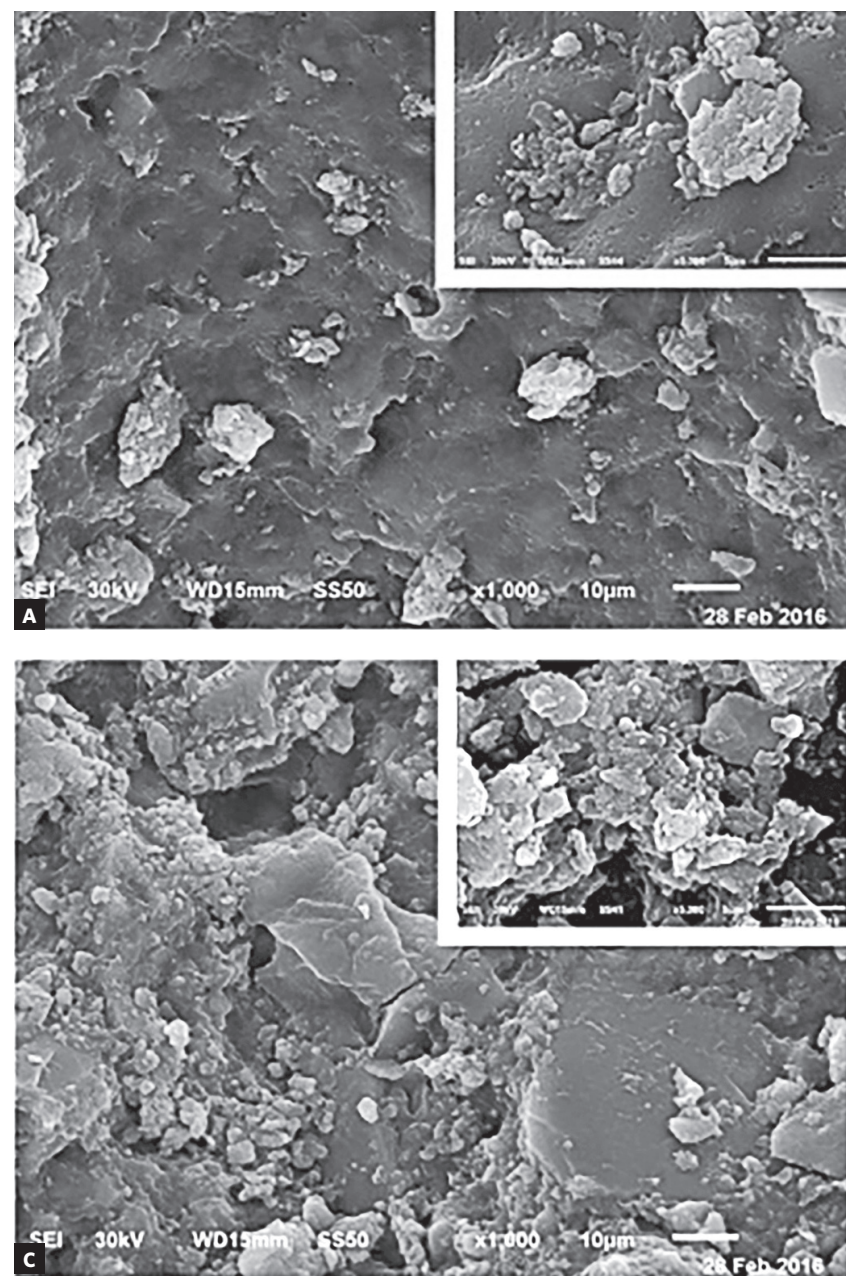

\section{Statistical analysis}

Data were analyzed with SPSS version 21. One-way analysis of variance was used to compare SBS followed by the post-hoc Tukey test. The chi-square test was used to evaluate differences in ARI scores among the groups.
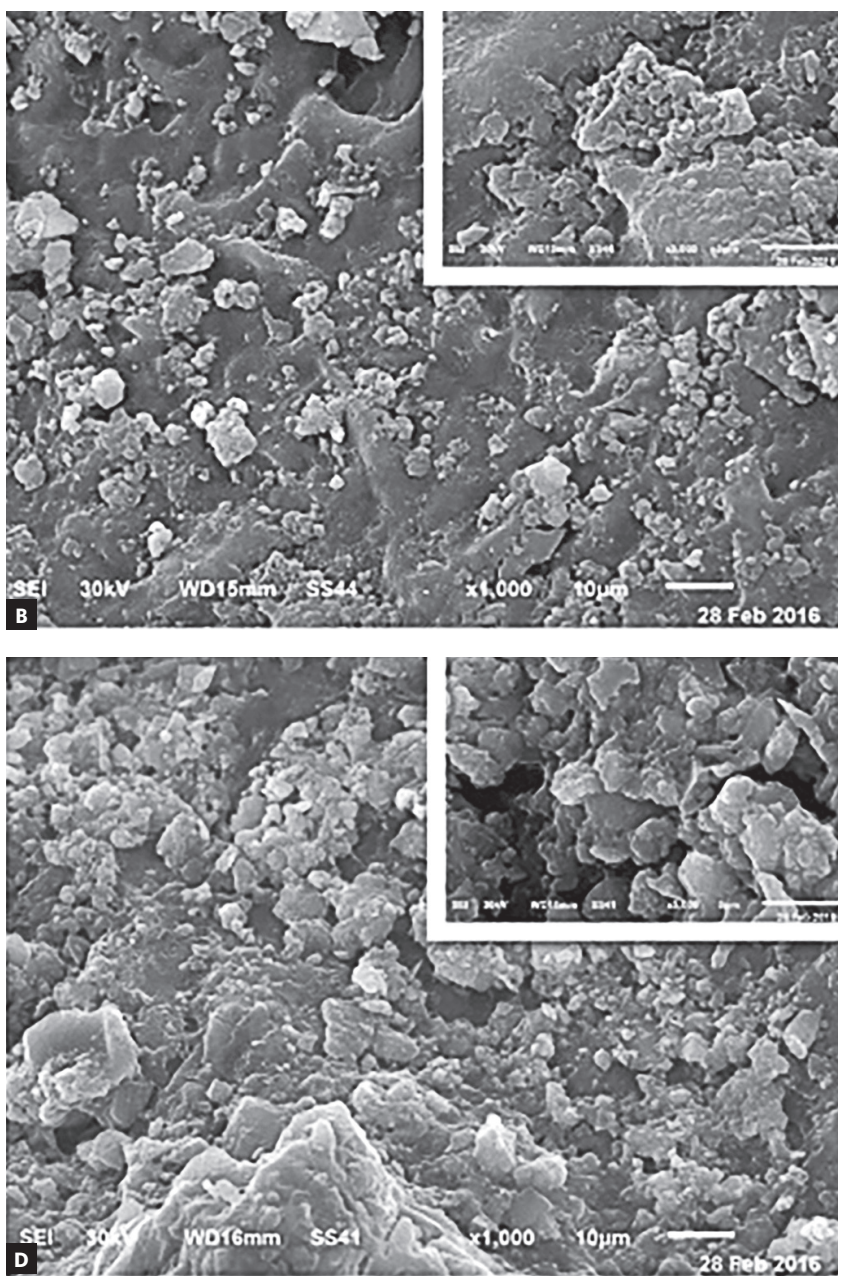

Figure 2 - Representative SEM photomicrographs of the two nanofilled bonding systems: Futurabond DC after 12 hours (A) and 24 hours (B); Optibond All-in-One after 12 hours (C) and 24 hours (D). 

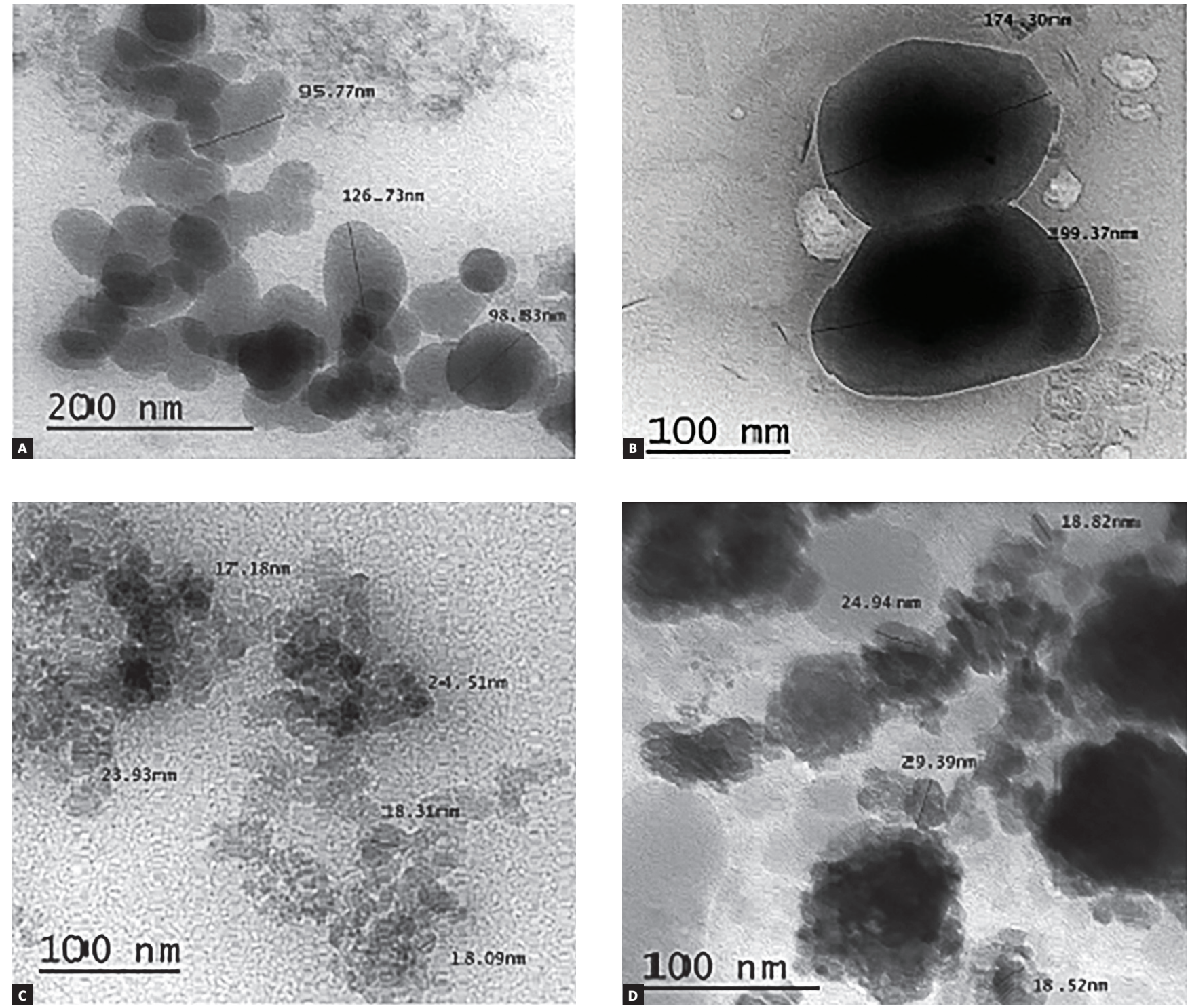

Figure 3 - Representative TEM photomicrographs of the four used bonding systems; Transbond XT primer of conventional system (A), Transbond Plus (B), Futurabond DC (C), Optibond All-in-One (D)

\section{RESULTS}

\section{Shear bond strength (SBS)}

The obtained SBS for the different four groups at 12 and 24 hours are given in Table 2. There were no statistically significant differences within each group at either time points $(p>0.05)$. Although the mean SBS observed with all different bonding systems at 12 hours were not statistically significant, the mean SBS obtained with the conventional system was statistically significant higher than that observed with Optibond All-in-One bonding system at 24 hours $(p<0.05)$.
Since there was no statistical significance of time points on the bond strength, the two subgroups (12 and 24 hours) were combined in Table 3. The combination showed that the SBS obtained with the two nanofilled systems used in this study were statistically significant lower than conventional system $(p<0.05)$, but there was no statistically significant difference between them. There was no statistically significant difference between the mean SBS obtained with Transbond Plus SEP and that obtained with other bonding systems. 
Table 2 - Shear bond strength values in megapascals of the bonding systems at 12 and 24 hours

\begin{tabular}{|c|c|c|c|c|c|c|}
\hline Time point & Bonding system & Mean & Standard deviation & Maximum & Minimum & p-value \\
\hline \multirow{4}{*}{12 hours } & A & 8.86 & 2.69 & 13.24 & 4.37 & \multirow{4}{*}{$p=0.199$} \\
\hline & B & 8.33 & 2.31 & 12.76 & 5.68 & \\
\hline & C & 7.19 & 2.52 & 11.17 & 3.93 & \\
\hline & $D$ & 7.03 & 2.13 & 11.29 & 3.81 & \\
\hline \multirow{4}{*}{24 hours } & A & $10.06^{a}$ & 3.02 & 14.53 & 5.49 & \multirow{4}{*}{$p=0.021^{\star}$} \\
\hline & $\mathrm{B}$ & 9.08 & 3.11 & 12.88 & 4.54 & \\
\hline & C & 7.27 & 2.40 & 10.67 & 4.36 & \\
\hline & D & $7.15^{b}$ & 1.61 & 9.43 & 4.78 & \\
\hline
\end{tabular}

( $\mathrm{A}=37 \%$ acid-etch and primer; $\mathrm{B}=$ Transbond plus; $\mathrm{C}=$ Futurabond DC; $\mathrm{D}=$ Optibond All-in-One). Groups with different superscript letters are statistically significantly different according to post-hoc Tukey HSD test, $\mathrm{p}=0.043$; *Significance was considered at $p<0.05$.

Table 3 - Shear bond strength values in megapascals of the bonding systems used in the study.

\begin{tabular}{|c|c|c|c|c|c|c|}
\hline Bonding system & $\mathbf{N}$ & Mean & Standard deviation & Maximum & Minimum & P-value \\
\hline A & 24 & $9.46^{a b}$ & 2.86 & 14.53 & 4.37 & \multirow{4}{*}{$p=.002^{*}$} \\
\hline B & 24 & 8.71 & 2.71 & 12.88 & 4.54 & \\
\hline C & 24 & $7.23^{a}$ & 2.41 & 11.17 & 3.93 & \\
\hline$D$ & 24 & $7.08^{b}$ & 1.85 & 11.29 & 3.81 & \\
\hline
\end{tabular}

( $\mathrm{A}=37 \%$ acid-etch and primer; $\mathrm{B}=$ Transbond plus; $\mathrm{C}=$ Futurabond DC; $\mathrm{D}=$ Optibond All-in-One). Groups with superscript letters present statistically significant difference according to post-hoc Tukey HSD test (between $\mathrm{A}$ and $\mathrm{C}, \mathrm{p}=0.013$; between $\mathrm{A}$ and $\mathrm{D}, \mathrm{p}=0.007$ ). ${ }^{\star}$ Significance was considered at $p<0.05$.

Table 4 - Distribution frequency of ARI scores for the bonding systems at debonding after $12 \mathrm{~h}$ and $24 \mathrm{~h}$.

\begin{tabular}{|c|c|c|c|c|c|c|c|c|c|c|}
\hline \multirow{2}{*}{$\begin{array}{l}\text { Bonding } \\
\text { systems }\end{array}$} & \multicolumn{4}{|c|}{12 hours } & \multirow{2}{*}{$\begin{array}{c}\mathrm{X}^{2} \\
\mathrm{p} \text {-value }\end{array}$} & \multicolumn{4}{|c|}{24 hours } & \multirow{2}{*}{$\begin{array}{c}\mathbf{X}^{2} \\
\text { p-value }\end{array}$} \\
\hline & 0 & 1 & 2 & 3 & & 0 & 1 & 2 & 3 & \\
\hline A & 0 & 8 & 4 & 0 & \multirow{4}{*}{$\begin{array}{c}X^{2}=5.85 \\
p=0.119 \\
\text { NS }\end{array}$} & 1 & 5 & 6 & 0 & \multirow{4}{*}{$\begin{array}{c}X^{2}=14.30 \\
P=0.112 \\
N S\end{array}$} \\
\hline$B$ & 0 & 10 & 2 & 0 & & 0 & 8 & 4 & 0 & \\
\hline C & 0 & 11 & 1 & 0 & & 1 & 10 & 1 & 0 & \\
\hline$D$ & 0 & 12 & 0 & 0 & & 1 & 10 & 0 & 1 & \\
\hline
\end{tabular}

NS, non-significant ( $A=37 \%$ acid-etch and primer; $B=$ Transbond plus; $C=$ Futurabond DC; $D=$ Optibond All-in-One).

\section{Adhesive remnant index (ARI) scores}

Table 4 shows that there was no statistically difference between the observed ARI scores on the four groups at 12 and 24 hours $(p>0.05)$. In addition, there was no statistically difference for each group at the two time points. The two nanofilled self-etch bonding systems showed a tendency towards the score 1 , however score 2 was noted in conventional system and Transbond Plus more than nanofilled systems at the two time points. These results indicated that there was less adhesive left on the enamel surface when the nanofilled bonding systems were used in this study.

\section{SEM examination}

The selected scanning electron photomicrographs were in accordance with the ARI stereomicroscope results. SE photomicrographs of total-etch system showed nearly even particles size that filled the porosities of etched enamel, and homogenous fillers distribution of bonding agent (Fig 1). Moreover, the scanning electron photomicrograph of Transbond Plus system showed a rather more condensed larger size particles with homogeneously distributed fillers on enamel that filled most of its porosities (Fig 1). Scanning electron microscope examination of the two nanofilled bonding systems revealed that the particles filled enamel po- 
rosities to an extent. The enamel porosities appeared smaller and shallower. These bonding agent systems seemed less homogeneous and had a tendency to aggregate in crowds and clusters. Photomicrograph of Optibond All-in-One showed larger size globular structures with higher concentration than DC and have more trends to accrue (Fig 2). SE microphotograph within each group showed that the bonding materials distribution was more homogeneous and showed more constancy when the debonding procedures were done after 24 hours in comparison with 12 hours (Fig 1 and 2).

\section{TEM examination}

Figure 3 shows transmission electron Microscope (TEM) results for the bonding systems used in the study. TEM photomicrograph of Transbond XT primer in conventional system and Transbond Plus showed larger size of separated and distributed fillers $(0.1 \mu \mathrm{m}$ and more $)$ and lesser filler concentration in comparison with nanofilled systems.

In nanofilled bonding systems (Futurabond DC and Optibond All-in-One), spherical nano-sized fillers had an average size of $20 \mathrm{~nm}$. Futurabond DC system had less concentration of nanofiller, which had more homogeneous distribution within the bonding agent, while Optibond All-in-One system had higher concentration of nanofillers that accumulate in dense clusters.

\section{DISCUSSION}

The bond strength of orthodontic brackets has to be appropriate to support masticatory and orthodontic forces. Although acid-etching technique is a common useful technique for direct bonding of orthodontic brackets to enamel, the developed SEP adhesive systems can reduce chair time, eliminate the risk of contamination and provide intact enamel surface at the end of treatment. By the time, modern technologies utilizing new materials and substances are constantly developing to improve the quality of the bracket bonding to tooth structures, such as nanotechnology. ${ }^{19}$

Nanoparticles (NPs) of various composition represent the most widespread use of nanotechnology in dentistry. ${ }^{7}$ Incorporated nanofillers in adhesives compositions increased resistance against fracture and wear, provided higher dimensional stability and produced higher SBS than conventional adhesives. ${ }^{20}$ Other studies reported comparable ${ }^{21,22}$ or lower but still acceptable shear bond strength, ${ }^{23,24}$ when nanofilled adhesives were used for bonding orthodontic brackets.

This study was conducted to evaluate the effect of spherical silicon dioxide $\left(\mathrm{SiO}_{2}\right)$ nanoparticles with average size of $20 \mathrm{~nm}$ added to two self-etch adhesive systems by the manufacturers with different concentrations (Futurabond DC; 1\% by weight and Optibond All-in-One; 7\% by weight) on the shear bond strength and mode of failure of stainless steel orthodontic brackets bonded to human enamel. The manufacturers claim that nanoparticles enhance bond strength, since they act as cross-links that promote the bond strength to enamel and dentin. In this regard, nano-sized fillers lead to entire permeation of the bond so they improve the bond strength.

Previous studies ${ }^{25,26}$ found that the shrinkage of polymerization was affected by the filler content, and another study ${ }^{7}$ indicated that greater shrinkage was produced by smaller nanofillers size, which leads to decreased bond strength of self-etch bonding systems.

Mean SBS values obtained in this study with the two nanofilled self-etch systems (Futurabond DC, $7.23 \pm 2.41 \mathrm{MPa}$; Optibond All-in-One, $7.08 \pm 1.85 \mathrm{MPa}$ ) were insignificantly smaller than mean SBS value of Transbond Plus $(8.71 \pm 2.71)$, but they were significantly smaller than the conventional system $(9.46 \pm 2.86 \mathrm{MPa})$. This might be attributed to the higher polymerization shrinkage produced by nano-sized particles. Moreover, SEM and TEM examination revealed that the nano-sized filled bonding systems had less homogeneous distribution than the others, so less number of enamel porosities was filled. It was revealed that less noticeable etching of enamel surface was acquired by self-etching primer system, and bonding resulted in smaller and fewer resin tags. ${ }^{27}$

There was no significant difference between mean SBS observed with the two nanofilled bonding systems. The SEM and TEM results showed that the nanoparticles in Optibond All-in-One had less homogeneous distribution and more tendency to aggregate in clusters. It was concluded that increasing nanofillers concentration within bonding systems had no effects on the shear bond strength of orthodontic brackets. 
The results observed in this study showed that Transbond Plus bonding system had comparable SBS with conventional system, this is similar to the findings of previous studies. ${ }^{4,5}$ On the other hand, self-etching bonding systems used in the study had a clinically acceptable mean SBS values since they were almost within the range (6-8 $\mathrm{MPa}$ ) recommended by Reynolds. ${ }^{28}$ However, only clinical testing can ensure clinical usefulness.

Testing of SBS at 24 hours after bonding procedure is generally preferred because it has been widely reported and allows comparison with other in vitro studies. However, initial stable time is highly important for clinical orthodontic practice, in which the archwire is usually placed after bracket bonding. ${ }^{29}$ Regarding our results, there were no statistically significant differences between SBS values obtained with each tested bonding systems at the two time points. Conventional system revealed values of $8.86 \pm 2.69$ and $10.06 \pm 3.02$ MPa; Transbond Plus, $8.33 \pm 2.31$ and $9.08 \pm 3.11 \mathrm{MPa}$; Futurabond DC, $7.19 \pm 2.52$ and $7.27 \pm 2.40 \mathrm{MPa}$; and Optibond All-in-One, $7.03 \pm 2.13$ and $7.15 \pm 1.61 \mathrm{MPa}$ at 12 and 24 hours, respectively. However, SEM evaluation showed more homogeneity and constancy in bonding materials after 24 hours. From a clinical point of view, it is therefore advisable not to load the brackets immediately to the maximum.

An ideal orthodontic adhesive should have adequate bond strength while maintaining unblemished enamel after debonding. The ARI is one of the most commonly used methods of assessing the quality of adhesion between the composite and tooth, as well as between the composite and bracket base. ${ }^{19}$ Regarding the present study, ARI scores were not significantly different from each other when time and bonding system were considered as variables.
Incomplete resin polymerization below the metal base of bracket usually occurs because the curing light cannot reach the adhesive behind the bracket mesh; for light-cured adhesive, most of the failures occurred at the adhesivebracket interface, which were similar to other findings. ${ }^{30}$ On the other hand, a score 2 of ARI was showed with conventional system and Transbond Plus in combination with a score 1 . However, the two nanofilled self-etch systems had a high tendency towards a score 1 . This could be clinically advantageous, because, when brackets fail at the enamel-adhesive interface, less adhesive remains, and tooth cleanup is likely to be easier and faster. ${ }^{19}$

\section{CONCLUSION}

"The two nano-filled bonding systems revealed clinically acceptable SBS and presented lower ARI scores than the other bonding systems tested.

"An appropriate bond strength was obtained after 12 hours. However, the adhesives had strengthened after 24 hours. 


\section{REFERENCES}

1. Buonocore MG. A simple method of increasing the adhesion of acrylic filling materials to enamel surfaces. J Dent Res. 1955 Dec;34(6):849-53.

2. Newman G. Current status of bonding attachments. J Clin Orthod. 1973 July:7(7):425-34 passim.

3. Mandall NA, Millett DT, Mattick CR, Hickman J, Worthington HV, Macfarlane TV. Orthodontic adhesives: a systematic review. J Orthod. 2002 Sept:29(3):205-10; discussion 195

4. Buyukyilmaz T, Usumez S, Karaman Al. Effect of self-etching primers on bond strength--are they reliable? Angle Orthod. 2003 Feb;73(1):64-70.

5. Grubisa HS, Heo G, Raboud D, Glover KE, Major PW. An evaluation and comparison of orthodontic bracket bond strengths achieved with selfetching primer. Am J Orthod Dentofacial Orthop. 2004 Aug;126(2):213-9; quiz 255

6. Silverstone LM, Saxton CA, Dogon IL, Fejerskov O. Variation in the pattern of acid etching of human dental enamel examined by scanning electron microscopy. Caries Res. 1975;9(5):373-87.

7. Başaran G, Ozer T, Devecioğlu Kama J. Comparison of a recently developed nanofiller self-etching primer adhesive with other self-etching primers and conventional acid etching. Eur J Orthod. 2009 June;31(3):271-5.

8. Mitra SB, Wu D, Holmes BN. An application of nanotechnology in advanced dental materials. J Am Dent Assoc. 2003 Oct:134(10):1382-90.

9. Saunders SA. Current practicality of nanotechnology in dentistry. Part 1: Focus on nanocomposite restoratives and biomimetics. Clin Cosmet Investig Dent. 2009 Nov 30;1:47-61. Print 2009

10. Argueta-Figueroa L, Scougall-Vilchis RJ, Morales-Luckie RA, Olea-Mejía OF An evaluation of the antibacterial properties and shear bond strength of copper nanoparticles as a nanofiller in orthodontic adhesive. Aust Orthod J. 2015 May; 31(1):42-8

11. Katona TR. Stresses developed during clinical debonding of stainless steel orthodontic brackets. Angle Orthod. 1997;67(1):39-46.

12. Stanford SK, Wozniak WT, Fan PL. The need for standardization of test protocols. Semin Orthod. 1997 Sept;3(3):206-9.

13. Whitlock BO 3rd, Eick JD, Ackerman RJ Jr, Glaros AG, Chappell RP. Shear strength of ceramic brackets bonded to porcelain. Am J Orthod Dentofacial Orthop. 1994 Oct;106(4):358-64.

14. Mitchell CA, O'Hagan E, Walker JM. Probability of failure of orthodontic brackets bonded with different cementing agents. Dent Mater. 1995 Sept:11(5):317-22

15. Trites B, Foley TF, Banting D. Bond strength comparison of 2 self-etching primers over a 3-month storage period. Am J Orthod Dentofacial Orthop. 2004 Dec:126(6):709-16

16. Bin Abdullah M, Rock WP. The effect of etch time and debond interval upon the shear bond strength of metallic orthodontic brackets. Br J Orthod. 1996 May:23(2):121-4
17. Turk T. Elekdag-Turk S, Isci D. Effects of self-etching primer on shear bond strength of orthodontic brackets at different debond times. Angle Orthod 2007 Jan;77(1):108-12

18. Artun J, Bergland S. Clinical trials with crystal growth conditioning as an alternative to acid-etch enamel pretreatment. Am J Orthod. 1984 Apr:85(4):333-40

19. Sharma S, Tandon P, Nagar A, Singh GP, Singh A, Chugh VK. A comparison of shear bond strength of orthodontic brackets bonded with four different orthodontic adhesives. J Orthod Sci. 2014 Apr;3(2):29-33.

20. Hegde MN, Hegde P, Bhandary S, Deepika K. An evalution of compressive strength of newer nanocomposite: An in vitro study. J Conserv Dent 2011;14(1):36-9

21. Ahn SJ, Lee SJ, Kook JK, Lim BS. Experimental antimicrobial orthodontic adhesives using nanofillers and silver nanoparticles. Dent Mater. 2009 Feb:25(2):206-13

22. Silva CFLM, Correa MA, Correr Sobrinho L, Moro A, Moresca RC, Correr GM. Shear bond strength of nanofilled flowable resins used for indirect bracket bonding. Braz J Oral Sci. 2012;11(4):458-62.

23. Uysal T, Yagci A, Uysal B, Akdogan G. Are nano-composites and nanoionomers suitable for orthodontic bracket bonding? Eur J Orthod. 2010 Feb:32(1):78-82

24. Machado CT, Borges BC, Araujo GJ, Santos AJ, Dametto FR, Pinheiro FH. Influence of adhesion promoters and curing-light sources on the shear bond strength of orthodontic brackets. Indian J Dent Res. 2012 NovDec:23(6):747-52

25. James JW, Miller BH, English JD, Tadlock LP, Buschang PH. Effects of high-speed curing devices on shear bond strength and microleakage of orthodontic brackets. Am J Orthod Dentofacial Orthop. 2003 May:123(5):555-61.

26. Faltermeier A, Rosentritt M, Faltermeier R, Reicheneder C, Müssig D Influence of filler level on the bond strength of orthodontic adhesives. Angle Orthod. 2007 May; 77(3):494-8

27. Fjeld M, Øgaard B. Scanning electron microscopic evaluation of enamel surfaces exposed to 3 orthodontic bonding systems. Am J Orthod Dentofacial Orthop. 2006 Nov:130(5):575-81

28. Reynolds I. A review of direct orthodontic bonding. Br J Orthod. 1975:2(3):171-8

29. Yamamoto A, Yoshida T, Tsubota K, Takamizawa T, Kurokawa H, Miyazaki M. Orthodontic bracket bonding: enamel bond strength vs time. Am J Orthod Dentofacial Orthop. 2006 Oct;130(4):435.e1-6.

30. Jou GL, Leung RL, White SN, Zernik JH. Bonding ceramic brackets with light-cured glass ionomer cements. J Clin Orthod. 1995 Mar:29(3):184-7. 